\title{
The impact of direct and indirect taxes on economic growth: An empirical analysis related to Romania
}

\author{
Ramona - Mihaela BÂZGAN \\ The Bucharest University of Economic Studies, Bucharest, Romania \\ bazgan.ramona.mihaela@gmail.com
}

\begin{abstract}
The purpose of this paper involved studying the impact of direct taxes and indirect taxes on the economic growth using an econometric Vector Autoregressive model (VAR) based on the statistical data related to Romania over the period of time 2009 (2 $2^{\text {nd }}$ quarter)-2017 (2 ${ }^{\text {nd }}$ quarter). Fiscal policy system involved a significant impact on the evolution of economic growth in the recent years in Romania, namely the years taken into consideration for this study. The econometric model used three endogenous variables, namely the level of direct taxes as percent of the Gross Domestic Product (\%GDP), the level of indirect taxes as percent of the Gross Domestic Product (\%GDP) and the economic growth rate over the analysed period of time. According to the econometric model presented in this paper, it was proved that a positive change in the structure of indirect taxes will have a strong positive influence on the economic growth over a medium-term period. On the other hand, economic growth will be negatively influenced in the next period of time after implementing a positive change in the structure of direct taxes, then returning to a positive influence over a medium term period and maintaining that influence in the future time periods.
\end{abstract}

Keywords: direct taxes, indirect taxes, economic growth, Vector Autoregressive model, impulseresponse function.

\section{Introduction}

Fiscal policies could lead to changes in the tax revenues of a country, then having a significant impact on the evolution of public revenues, subsequently contribute to the covering of public spending, contribute to the stabilization and consolidation process of the entire economic performance of the state, influence the allocation of new public financial resources and are also seen as a support for the economic growth. Public authorities of each state will need to develop and search for sustainable fiscal and administrative measures that could lead to medium or long-term economic growth.

This paper will attempt to explain the impact of direct taxes as well as indirect taxes on the economic growth along with the determination of what types of taxes will contribute mostly to an effective and sustainable economic growth by using time series data corresponding to Romania. A Vector Autoregressive model ("VAR") will be determined to analyze whether the economic growth related to Romania was recorded due to the performance of some fiscal policies implemented in the last years. The analysis is adjusted and extended over time series data related to Romania during the period of $2009\left(2^{\text {nd }}\right.$ quarter $)-2017$ (2 $2^{\text {nd }}$ quarter $)$.

The paper is structured as follows: The first part involves a research on the literature that emphasized the recent empirical analysis over the impact of tax revenue on the economic growth. The second section comprises the structure of direct and indirect taxes as percent of Gross Domestic Product (\%GDP) over the data related to member states of the European Union (EU-28). The estimation of the economic growth in Romania compared with that from EU-28 in the recent years will also be explained. The second part 
reveals also the econometric methodology used for the development of the VAR model along with the interpretation of each endogenous variable chosen based on the time series data used for the analysis. The third part contains the results of the VAR model by implementing the impulse response function. The fourth part sums up as a conclusion the impact of any change in the structure of direct and indirect taxes on economic growth over a future period of time.

PICBE $\mid 115$

As subsequently explained, the model was developed on time series data related to Romania. On the assumption that the model will prove to be valid and also if it could explain the impact of fiscal policies on the economic growth, this econometric model can be used further over time series data from any country in case that the impact of fiscal policies on economic growth should be revealed. The validity of the model will be checked under the following conditions: by using VAR Residual Probability Test, VAR Residual Serial Correlation LM Test and also by testing the heteroskedasticity of the analyzed VAR model.

\section{Literature review}

Most empirical studies tend to have as a main concern the interpretation of the impact of changes in the structure of the tax revenue on economic growth and, as a second matter, the impact of each type of tax on the economic growth. There are many empirical studies that explain through economically models the impact of direct or indirect taxes on economic growth as a concern that the structure and the level of tax revenues are a part of a country's fiscal policy aimed to contribute to the sustainability, to the increasing in public revenues, to the sustaining of the public spending, finance the investments made by the states, and consequently lead to economic growth.

A recent empirical study by Dasislava (2017) developed an econometric model built on the basis of regressions over a pooled panel data on EU-28 for the period of 1996-2013. The econometric model revealed that production taxes along with import taxes had a greater positive impact on economic growth than property taxes that are neutral in terms of economic growth. Taxes on individuals have also a positive impact on the evolution of economic growth, but contribute less than taxes applied, as an example, to import. The econometric study used as dependent variable the growth rate of the Gross Domestic Product ("GDP") and as independent variables: total government expenditure, total income from taxes, social contributions and budgetary balance.

Mura (2015) applied an empirical model to study the impact of the tax structure on the evolution of economic growth based on panel series related to six countries across Eastern Europe over the period of 1995-2012. Specifically, the study is based on the impact of the various tax revenue fundamentals (direct and indirect taxes as a percentage of total tax revenue) on economic growth. The empirical output suggested that direct taxes are significantly correlated negatively with economic growth while indirect taxes generate a positive influence on the dependent variable represented by the economic growth. Governments must continue to shift the tax burden on labor and rely it on taxes based on consumption or on property taxes that will have potential positive effects on economic growth.

Stailova \& Patonov (2012) determined an empirical study for analyzing the impact of taxes on economic growth. It has been demonstrated that the impact of direct taxes on 
economic growth is significant because of the fact that direct taxes are more cost-effective for EU countries. Indirect taxes revealed a tendency to lower the budget revenues due to the inequality in the structure of indirect taxes. The analysis was based on EU-27 statistical data over the period 1995-2010. A regression model was used by using as variables the taxto-GDP ratio and the tax structure such as the value of direct taxes, indirect taxes and social contributions.

PICBE $\mid 116$

Brașoveanu \& Brașoveanu (2008) have analyzed the correlation between fiscal policy and economic growth related to Romania over the period of 1990-2007. The study revealed a negative correlation between budgetary revenues and the economic growth. The study had classified taxes according to their effects on private agents and viewed them as distortionary revenues, non-distortionary revenues and other revenues. It was revealed a negative effect between non-distortionary taxes, distortionary taxes and economic growth. The variables used for the estimation of the regression were the rate of real GDP growth, fiscal revenues on GDP, distortionary fiscal revenues (personal income taxes, corporate income taxes, social security contributions, property taxes) and non-distortionary fiscal revenues (such as value added tax and excise duties).

Mutașcu \& Dănulețiu (2011) analyzed an empirical study based on a vector autoregressive model on time series related to Romania for the period of January 1999 March 2010 using as endogenous variables the rate of dynamic economic growth and dynamic taxation's level. It was proved that a positive impact on the tax revenue will determine a decrease in the economic growth while a positive impulse in the economic growth will increase the level of tax revenues in the long-run. Regarding the positive impulse in the tax revenue, it was proved that this could affect by a low intensity the economic growth in the first two years, maintaining then a significant impact for a long-run period of time.

Szarowska (2011) analyzed the effect of changes in the structure of taxes on economic growth using annual series for EU-24 member states over a period of time between 1995 and 2008. The effect of the tax quota changes on economic growth along with the effect of changing the structure of social contributions, direct taxes and indirect taxes on economic growth were analyzed. It was also taken into consideration the impact of changing the structure of corporate income tax and personal income tax on economic growth. The analyzed empirical studies had shown that the total tax burden will have a negative impact on the evolution of economic growth. The model showed a significant negative impact of direct taxes on economic growth. As far as social contributions are concerned, they are not statistically significant for the estimation of the impact on economic growth.

\section{Methodology}

The evolution of the value of direct taxes, indirect taxes and economic growth in recent years in $\mathrm{EU}-28$

In reference to the empirical analysis, this paper tend to forecast the impact of changing the structure of direct taxes and indirect taxes on economic growth. In order to perform the econometric model, there were used three endogenous variables, namely the level of indirect taxes as a percent of Gross Domestic Product (\%GDP), the level of direct taxes as a 
percent of Gross Domestric Product (\%GDP) and the rate of economic growth (\%). Exogenous variables were not used as it was intended to explain the impact of indirect taxes and direct taxes on economic growth without taking into account other external economic indicators that can generate an influence on the economic growth.

The analysis is based on the use of quarterly time series from 2009 ( $2^{\text {nd }}$ quarter) to 2017 ( $2^{\text {nd }}$ quarter) on a totally of 33 observations. The statistical data were collected from the Eurosat database related to the state of Romania. No time series data were collected or explained about the evolution of social contributions on the economic growth. According to the European System of Accounts - ESA 2010, the classification of taxes over the EU member states is comprised as following: taxes on production and imports (indirect taxes), current taxes on wealth (direct taxes) and capital taxes.

Regarding the annual time series data on EU-28 member countries over the recent years, it was determined a trend of increase in the value of indirect tax and a trend of decrease in the evolution of the compiled direct taxes. Graph 1 reveals the evolution of direct taxes and indirect taxes as a percentage of GDP within the EU-28 member states in the reporting year 2016. According to the European Comission (2017a), the higher level of indirect taxes collected as percent of GDP (\%GDP) in 2016 was registered in Sweden 22.4\%, followed by Croatia 19.4\%, Hungary 18.2\%, Greece 17.2\%, Denmark 16.4\%. Regarding Romania, when taking into consideation the level of indirect taxes, it was collected only $11.3 \%$ as a percent of GDP above the value of EU-28 which registered $13.4 \%$. On the other hand, regarding the value of direct taxes collected as a percent of GDP (\%GDP), the higher level was registered in Denmark 29.8\%, followed by Sweden 18.7\%, Finland 16.5\%, Belgium 16.2\%. The lowest level was registered in Bulgaria 5.4\%, followed by Lithuania $5.7 \%$, Romania $6.5 \%$, Croatia $6.6 \%$, Poland $7.1 \%$. The value of direct taxes collected as a percent of GDP in Romania is less than the value of EU-28 (\%GDP) where there was registered a level of $13 \%$ as percent of GDP.

\section{Graph 1.The evolution of direct and indirect taxes (\%GDP) in EU-28 over the fiscal year 2016}

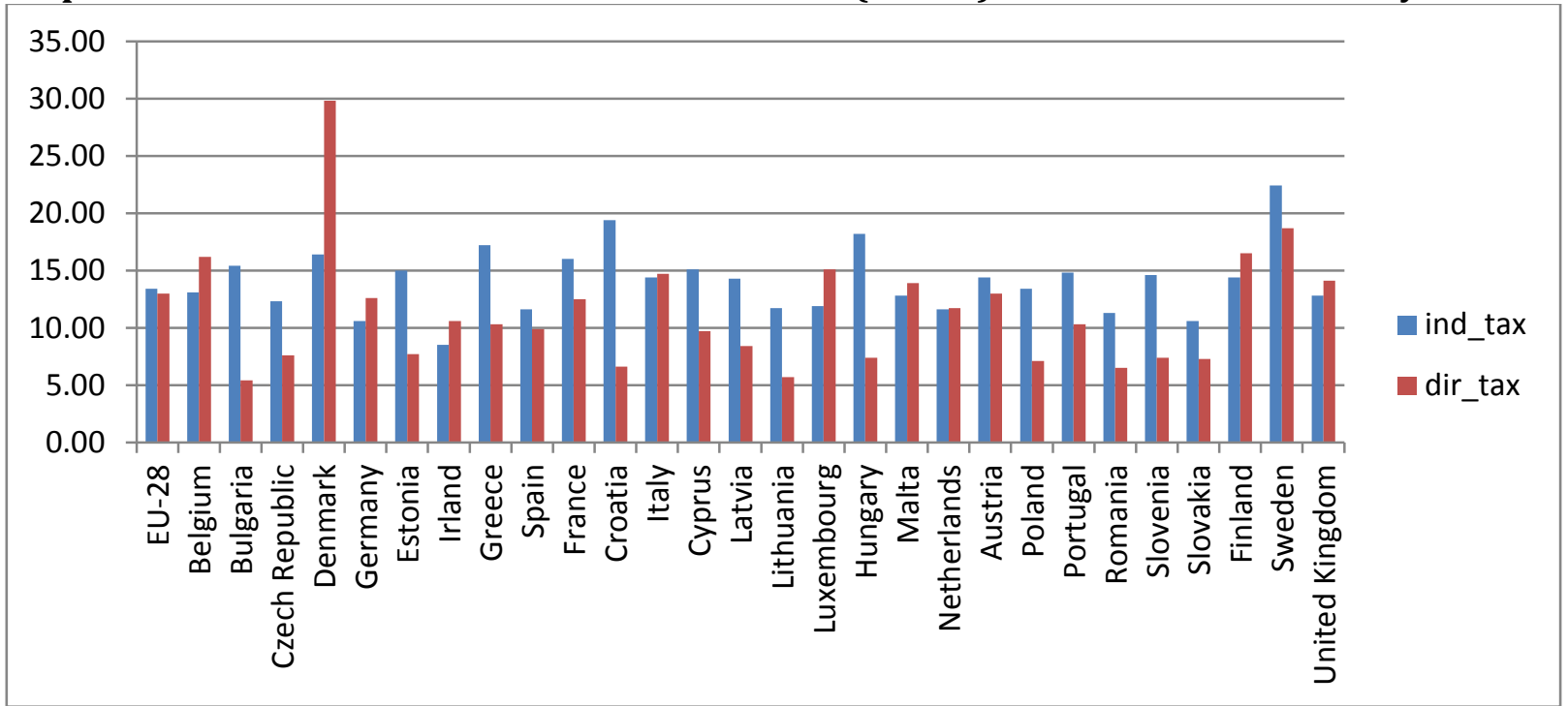

Source: Author's own research using time series data from Eurostat database. 
On the other hand, Graph 2 explains the annual evolution of the economic growth registered for Romania compared to the evolution of EU-28 member states over the last years. It was revealed an increasing trend based on the data collected, but starting with the year 2012 the increase in GDP growth rate in Romania was higher than that registered for EU-28. The economic growth of Romania was explained under the increasing of private consumption in the recent years.

\section{Graph 2.The evolution of the economic growth related to Romania in comparison with the economic growth value registered for EU-28 (2009-2016)}

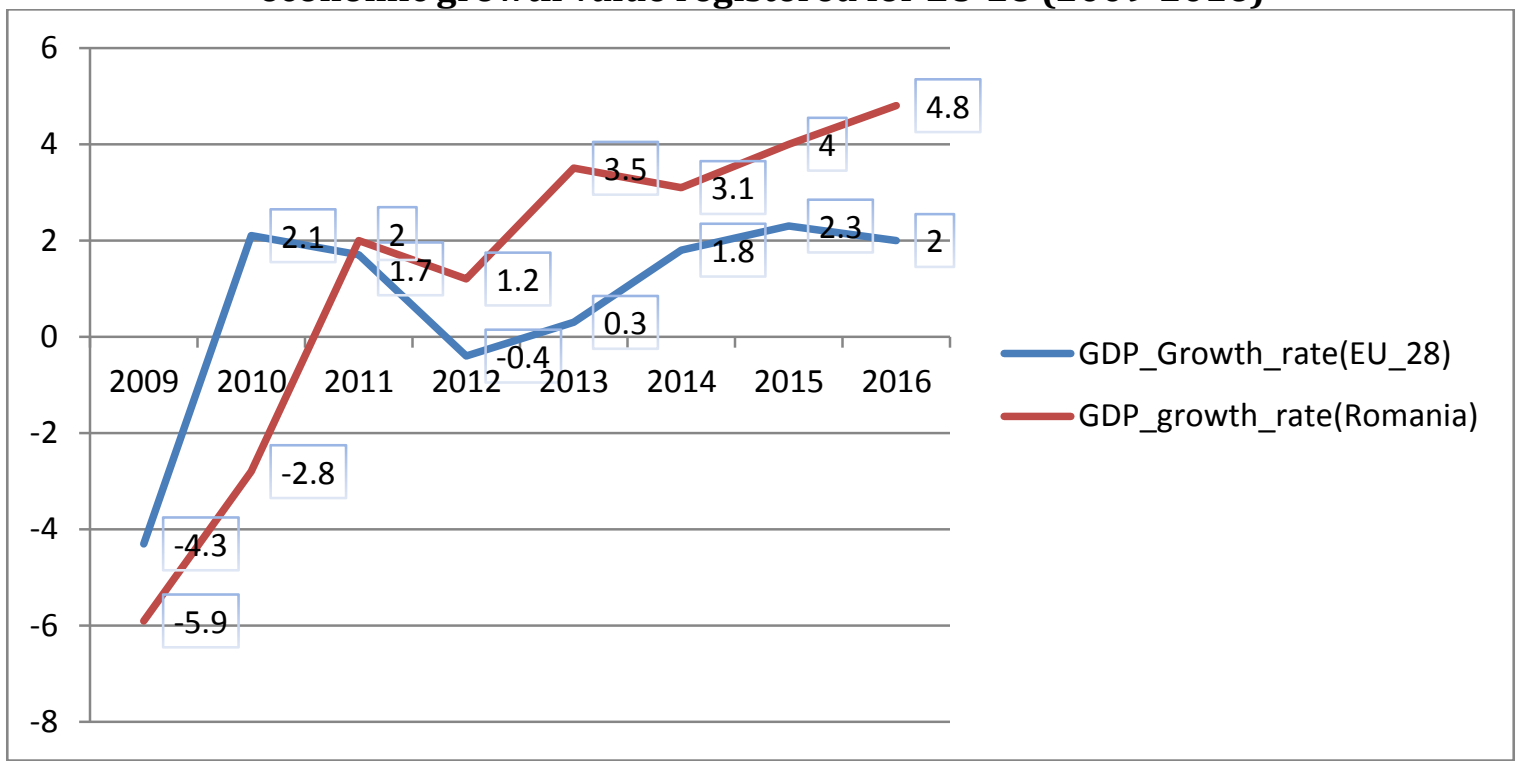

Source: Author's own research using time series data from Eurostat database.

Fiscal policies implemented in the EU member states tended to be expansionary and developed under policies of stabilization and consolidation of the economies of the states in the last years in order to correct the excessive deficits registered during the time period of economic crisis. (European Central Bank, 2017a)

Regarding the fiscal policies related to Romania, these tended to be pro-cyclical expansionary due to the tax administrative strategies implemented in the last years which were based especially on decreasing g the value of tax base for some significant taxes such as the value added tax which leaded further to an increase on the private consumption. On the other hand, the value of exports contributed negatively to the evolution of economic growth due to the fact that the value of exports related to Romania tended to decrease over the last few years. Thus, Romania registered an economic growth at a value level of $4.8 \%$ in 2016 which was based on the increase of private consumption (European Commission, $2017 \mathrm{~b}$ ). In the recent years, a major fiscal policy in Romania was represented by the decrease in the value of added tax rate from $24 \%$ to $20 \%$ in 2016 , and then to $19 \%$ starting with 2017. Starting with 2015, the value added tax rate for food products was cut up to a rate of $9 \%$. Starting with 2016, tax base related to incomes on dividends was taxed from 
$16 \%$ to a rate of $5 \%$. Starting with 2018 , income tax rate for individuals decreased from $16 \%$ to $10 \%$. (European Commission, 2017c)

The impact of tax polices represents a significant relevance in generating sustainable economic growth. The analyzed econometric study used as endogenous variables the level of indirect tax rate as a percentage of GDP, the level of direct taxes reported as a percentage of GDP and the economic growth rate.

\section{Vector Autoregressive Model Approach}

Based on the time series data collected, an econometric Vector Autoregressive model (VAR) was estimated in order to explain the relationship between indirect taxes, direct taxes and the economic growth. The Eviews software was used in order to process the time series data collected from the Eurostat database. (Eurostat database, 2017) Table 1 explains the notations used in the analyzed VAR model.

Table 1. Notes of the variables chosen in the VAR model estimation

\begin{tabular}{|l|l|}
\hline The name of the variable & Notations \\
\hline Level of direct taxes(\%GDP) - mil. Euro & dir_taxes \\
\hline Level of indirect taxes(\%GDP) - mil. Euro & ind_taxes \\
\hline Economic growth rate(\%) & gdp_growth_rate \\
\hline
\end{tabular}

The VAR model used to explain the impact of direct taxes and indirect taxes on the economic growth will be represented by the following equation:

$$
\begin{aligned}
& \text { gdp_growth_rate } 1 \mathrm{t}=\alpha+\beta_{1} \text { gdp_growth_rate }_{\mathrm{t}-1}+\beta_{2} \text { gdp_growth_rate } \mathrm{t}_{-2}+\ldots . .+
\end{aligned}
$$

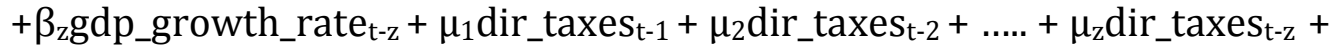

$$
\begin{aligned}
& +\Upsilon_{1} \text { ind_taxest-1 }+\Upsilon_{2} \text { ind_taxest }-2_{-}+\ldots .+\Upsilon_{\mathrm{z}} \text { ind_taxes }_{\mathrm{t}-\mathrm{z}}+\varepsilon_{\mathrm{t}}
\end{aligned}
$$

Where gdp_growth_rate variable depends on time series data from the past, thus being subsequently included in the model other variables that can explain the changes in the value of gdp_growth_rate. For revealing more exactly the impact of dir_taxes and ind_taxes on gdp_growth_rate, these two endogenous variables were included up to a p defined lags. $\alpha$ is a constant term , $\varepsilon_{t}$ represents the stochastic error term and $\beta, \mu$ and $\Upsilon$ represent the coefficients that can have proportionally an impact on economic growth, $\mathrm{z}$ is a notation which refers to the fact that time series start from $\mathrm{z}$ and end up to a $\mathrm{p}$ number of lags. The selection of $p$ lags will be later explained.

The first step in estimating the VAR model is the use of root test that confirm the condition of stationarity for each chosen endogenous variables. Unit root tests for variables are based on the Augmented Dickey-Fuller unit root test. The results generated by the Eviews program related that all three endogenous variables are stationary, which meant that dir_taxes, ind_taxes and gdp_growth_rate were integrated at unit root at level I(0). There was confirmed no first difference or first order integration. 
Table 2. Augmented Dickey-Fuller test

\begin{tabular}{|l|l|l|l|l|}
\hline $\begin{array}{l}\text { Unit root at Level (with intercept } \\
\text { and trend) }\end{array}$ & P-value & T-static & Critical value \\
\hline Variables & dir_taxes & 0.0215 & -3.33 & $-2.95^{* *}$ \\
\hline & ind_taxes & 0.0305 & -3.18 & $-2.95^{* *}$ \\
\hline & gdp_growth_rate & 0.0000 & -8.94 & $-3.66^{*}$ \\
\hline
\end{tabular}

PICBE $\mid 120$

Asterisks $(* *, *)$ denote statistically significant values at $1 \%$ and $5 \%$ level.

Source: Author's own research.

Regarding the significance of the p-value for each analyzed endogenous variable, it was exposed that the p-value is less than $5 \%$ for all the chosen variables. Taking also into consideration the fact that for all the variables the value of t-static is less than the critical value, the null hypothesis was rejected which meant that the analyzed series are stationary at level unit root integrated I(0). Subsequently, for the determination of the VAR model, it would be useful to check the cointegration between the analyzed endogenous variables.

Unrestricted Cointegration Rank Test (Trace)

\begin{tabular}{ccccc}
\hline \hline $\begin{array}{c}\text { Hypothesized } \\
\text { No. of CE(s) }\end{array}$ & Eigenvalue & $\begin{array}{c}\text { Trace } \\
\text { Statistic }\end{array}$ & $\begin{array}{c}0.05 \\
\text { Critical Value }\end{array}$ & Prob. $^{\text {** }}$ \\
\hline \hline None & 0.500131 & 23.02637 & 24.27596 & 0.0713 \\
At most 1 & 0.027266 & 1.530685 & 12.32090 & 0.9793 \\
At most 2 & 0.021498 & 0.673700 & 4.129906 & 0.4715 \\
\hline \hline
\end{tabular}

Trace test indicates no cointegration at the 0.05 level

* denotes rejection of the hypothesis at the 0.05 level

${ }^{* *}$ MacKinnon-Haug-Michelis (1999) p-values

Figure 1. Cointegration Rank Test for the VAR Model (Johansen Cointegration Test)

Source: Author's own research.

Figure 1 shows that there is no cointegration between the endogenous variables chosen for the analyzed unrestricted Vector Autoregressive model (VAR). Due to the fact that variables were not cointegrated, a VAR model could have been determined in order to explain the impact of direct taxes and indirect taxes on the economic growth. The next step for the estimation of the VAR model would include the selection of the lags. The optimal number of lags will be chosen by using the Akaike Information Criterion (AIC) and the Schwartz Criterion (SBC) which meant choosing the lowest value of them along with the probability of using a model which contains the lowest number of criteria.

Table 3. VAR Lag Order Selection Criteria

\begin{tabular}{|l|l|l|}
\hline Number of the lag & AIC & SBC \\
\hline 0 & 12.18331 & 12.31935 \\
\hline 1 & $11.99063^{*}$ & $12.54028^{*}$ \\
\hline 2 & 12.02653 & 12.99794 \\
\hline 3 & 12.39082 & 13.79201 \\
\hline 4 & 11.56948 & 13.40826 \\
\hline 5 & 11.72592 & 14.00969 \\
\hline
\end{tabular}

Source: Author's own research. 
According to the previous selection, it was revealed that the chosen VAR model would be displayed at a number of 1 lag. The lowest values were chosen for both Akaike Information Criterion (AIC) and Schwartz Criterion (SBC). At lag 1 the data series would be significantly to explain the impact of direct taxes and indirect taxes on economic growth.

\begin{tabular}{|c|c|c|c|}
\hline & DIR_TAXES & GDP_GRO... & IND_TAXES \\
\hline DIR_TAXES(-1) & $\begin{array}{l}0.516656 \\
(0.17952) \\
{[2.87793]}\end{array}$ & $\begin{array}{r}-0.173853 \\
(0.20184) \\
{[-0.86133]}\end{array}$ & $\begin{array}{r}-0.052077 \\
(0.18169) \\
{[-0.28662]}\end{array}$ \\
\hline GDP_GROWTH_RATE $(-1)$ & $\begin{array}{r}-0.136476 \\
(0.16159) \\
{[-0.84458]}\end{array}$ & $\begin{array}{r}-0.127955 \\
(0.18168) \\
{[-0.70428]}\end{array}$ & $\begin{array}{l}0.172797 \\
(0.16354) \\
{[1.05657]}\end{array}$ \\
\hline IND_TAXES(-1) & $\begin{array}{r}-0.220274 \\
(0.18069) \\
{[-1.21906]}\end{array}$ & $\begin{array}{l}0.363133 \\
(0.20316) \\
{[1.78745]}\end{array}$ & $\begin{array}{l}0.461243 \\
(0.18288) \\
{[2.52217]}\end{array}$ \\
\hline$c$ & $\begin{array}{l}7.680309 \\
(2.19228) \\
{[3.50335]}\end{array}$ & $\begin{array}{c}1.385445 \\
(2.46484) \\
{[0.56208]}\end{array}$ & $\begin{array}{r}4.162509 \\
(2.21877) \\
{[1.87604]}\end{array}$ \\
\hline $\begin{array}{l}\text { R-squared } \\
\text { Adj. R-squared } \\
\text { Sum sq. resids } \\
\text { S.E. equation } \\
\text { F-statistic } \\
\text { Loglikelihood } \\
\text { Akaike AlC } \\
\text { Schwarz SC } \\
\text { Mean dependent } \\
\text { S.D. dependent }\end{array}$ & $\begin{array}{l}0.241445 \\
0.160172 \\
77.70062 \\
1.665840 \\
2.970770 \\
-59.60007 \\
3.975004 \\
4.158221 \\
12.50028 \\
1.817766\end{array}$ & $\begin{array}{r}0.115185 \\
0.020383 \\
98.22221 \\
1.872949 \\
1.215007 \\
-63.34998 \\
4.209374 \\
4.392591 \\
1.448825 \\
1.892334\end{array}$ & $\begin{array}{l}0.229295 \\
0.146719 \\
79.58989 \\
1.685970 \\
2.776784 \\
-59.98445 \\
3.999028 \\
4.182245 \\
6.841972 \\
1.825172\end{array}$ \\
\hline \multicolumn{2}{|c|}{$\begin{array}{l}\text { Determinant resid covariance (dof adj.) } \\
\text { Determinant resid covariance } \\
\text { Log likelihood } \\
\text { Akaike information criterion } \\
\text { Schwarz criterion }\end{array}$} & $\begin{array}{r}22.81898 \\
15.28693 \\
-179.8501 \\
11.99063 \\
12.54028\end{array}$ & \\
\hline
\end{tabular}

Figure 2. The deployment of the Vector Autoregression Model (VAR)

Source: Author's own research.

The result indicated that there would be considered three dependent and endogenous equations, namely ind_taxes, dir_taxes and gdp_growth_rate. Each variable will have a number of 1 lag taken into consideration the lag selection criteria which was previously presented. The estimation of this VAR model along with the projection of its coefficients could lead further to the explication on which coefficients of variables dir_taxes or ind_taxes could have any influence on the gdp_growth_rate variable or if the coefficients of the VAR model are significant to explain the evolution of the gdp_growth_rate variable. The estimated model would be represented by three dependent variables dir_taxes, ind_taxes and gdp_growth_rate each one having 4 coefficients including the coefficients related to the constant $c$. To sum up, the VAR model will consist in 12 coefficients. The coefficients that would significantly determine each dependent variable would have a p-value less than $5 \%$. For example, taking into the consideration the data presented in figure 2 , the coefficient of dir_taxes at lag 1 is equal to -0.173853 . By implementing this VAR model it could be determined which coefficients are significant to explain the gdp_economic_growth. The most significant coefficients would have a p-value at less than $5 \%$. 


\begin{tabular}{crrrr}
\hline \hline & Coefficient & Std. Error & t-Statistic & Prob. \\
\hline \hline$C(1)$ & 0.516656 & 0.179524 & 2.877925 & 0.0051 \\
$C(2)$ & -0.136476 & 0.161591 & -0.844575 & 0.4007 \\
$C(3)$ & -0.220274 & 0.180692 & -1.219059 & 0.2262 \\
$C(4)$ & 7.680309 & 2.192278 & 3.503347 & 0.0007 \\
$C(5)$ & -0.173853 & 0.201843 & -0.861327 & 0.3915 \\
$C(6)$ & -0.127955 & 0.181682 & -0.704283 & 0.4832 \\
$C(7)$ & 0.363133 & 0.203157 & 1.787452 & 0.0775 \\
$C(8)$ & 1.385445 & 2.464837 & 0.562084 & 0.5756 \\
$C(9)$ & -0.052077 & 0.181693 & -0.286622 & 0.7751 \\
$C(10)$ & 0.172797 & 0.163544 & 1.056575 & 0.2937 \\
$C(11)$ & 0.461243 & 0.182875 & 2.522174 & 0.0136 \\
$C(12)$ & 4.162509 & 2.218770 & 1.876044 & 0.0641 \\
\hline \hline
\end{tabular}

PICBE | 122

Figure 3. The estimation of the p-value related to each coefficient included in the VAR model

Source: Author's own research.

Figure 3 represented the measurement of the p-value for each coefficient that could influence the analyzed VAR econometric model. Regarding the estimation of the p-value by individual testing, the significant coefficients for the chosen model are coefficient $\mathrm{C}(1), \mathrm{C}(4)$ and $\mathrm{C}(11)$ since they had a p-value of less than 5\%. This demonstrated that the variables chosen had correlations between them and that the impulsive response function could be further explained if there was registered any change in the structure or the level of each endogenous variable. By using the Wald Coefficient test, it could be used the joint significance to determine which coefficients could affect together and not individually the change on the gdp_growth_rate. In figure 4, it would be determined whether the coefficient $\mathrm{C}(5)$ together with the coefficient C(7) would be able to influence together the variable of gdp_growth_rate using the Wald Coefficient test.

\begin{tabular}{|c|c|c|c|}
\hline Test Statistic & Value & df & Probability \\
\hline Chi-square & 3.278999 & 2 & 0.1941 \\
\hline
\end{tabular}

Figure 4. Wald Coefficient test

Source: Author's own research.

According to the figure 4, it could be revealed that the p-value is higher than $5 \%$, which meant that the null hypothesis was rejected. The null hypothesis indicated that coefficient $\mathrm{C}(5)$ and $\mathrm{C}(7)$ together are equal to 0 , which further represented that coefficient $\mathrm{C}(5)$ and C(7) cannot influence together the gdp_growth_rate variable. Since the VAR model was already estimated, it was also necessary to perform some steps in order to determine if the chosen VAR model is valid. 


\begin{tabular}{ccc}
\hline \hline Lags & LM-Stat & Prob \\
\hline \hline 1 & 12.74108 & 0.1747 \\
\hline \hline
\end{tabular}

Probs from chi-square with $9 \mathrm{df}$.

\section{Figure 5. Residual Serial Correlation LM test}

Source: Author's own research.

According to figure 5, p-value was less than 5\%, which indicated that the null hypothesis cannot be rejected. The null hypothesis supposed that there was no serial correlation between the residuals of the VAR model. This meant that there was no serial correlation, which revealed once again that the model was valid. Another way to indicate the validity of the chosen VAR model was to explain the heteroskedasticity of the model which was confirmed in the figure 6.

\begin{tabular}{ccc} 
Joint test: & & \\
\hline \hline Chi-sq & df & Prob. \\
\hline \hline 37.24745 & 36 & 0.4115 \\
\hline \hline
\end{tabular}

Figure 6. Heteroskedasticity - Breusch- Pagan- Godfrey test

Source: Author's own research.

Time series data do not usually reveal heteroskedasticity. As shown in figure 6, the pvalue is less than $5 \%$, which meant the null hypothesis cannot be rejected. The null hypothesis estimated that there was no heteroskedasticity. Thus, it was determined that the model is valid. According to the literature based on econometrics, another way to check the validity of the chosen model is to confirm whether residuals are normally distributed.. Figure 7 explained the VAR residual probability test. 


\begin{tabular}{|c|c|c|c|c|}
\hline Component & Skewness & Chi-sq & df & Prob. \\
\hline 1 & 1.231873 & 8.101936 & 1 & 0.0044 \\
\hline 2 & 0.462373 & 1.458754 & 1 & 0.2271 \\
\hline 3 & 0.693993 & 3.090718 & 1 & 0.0787 \\
\hline Joint & & 12.65141 & 3 & 0.0055 \\
\hline Component & Kurtosis & Chi-sq & df & Prob. \\
\hline 1 & 6.527005 & 3.118797 & 1 & 0.0774 \\
\hline 2 & 2.906070 & 0.006064 & 1 & 0.9379 \\
\hline 3 & 2.686379 & 1.798722 & 1 & 0.1799 \\
\hline Joint & & 4.923583 & 3 & 0.1775 \\
\hline Component & Jarque-Bera & df & Prob. & \\
\hline 1 & 11.22073 & 2 & 0.0037 & \\
\hline 2 & 1.464818 & 2 & 0.4807 & \\
\hline 3 & 4.889440 & 2 & 0.0868 & \\
\hline Joint & 17.57499 & 6 & 0.0074 & \\
\hline
\end{tabular}

Figure 7. VAR Residual Probability Test

Source: Author's own research.

Following the Jarque-Bera results, the probability for model 2 which represented that the variable gdp_growth_rate higher than $5 \%$, which confirmed that the null hypothesis cannot be rejected. The null hypothesis estimated that residuals are normally distributed. It could be said that the model is valid because residuals are normally distributed. To sum up, due to the fact that the model had no serial correlation, it did not have heteroskedasticity, the residuals of this model were normally distributed and also due to the existence of individual coefficients that were significant for explaining the endogenous variables it was confirmed that the chosen VAR model was valid and significant for explaining the impact of direct taxes and indirect taxes on economic growth.

Further on, in order to explain the results that could be revealed by analyzing the estimated VAR model, the impulse response function was implemented. The impulse response function showed the evolution of the dependent variable when the independent variable would receive a positive shock. This would further explain the influence that the value or structure of direct and indirect taxes would have on the economic growth over a future period of time.

\section{Results and discussions}

This section revealed the impact of a positive change in the value of direct or indirect taxes on the growth rate. The impact would be explained using a forecasting for 10 quarters in the future time periods. The order of the variables is important for determining the impulse response function. The Cholesky decomposition method would be selected for the order of the variables, since only the endogenous variables prevailed in the analyzed VAR model. 


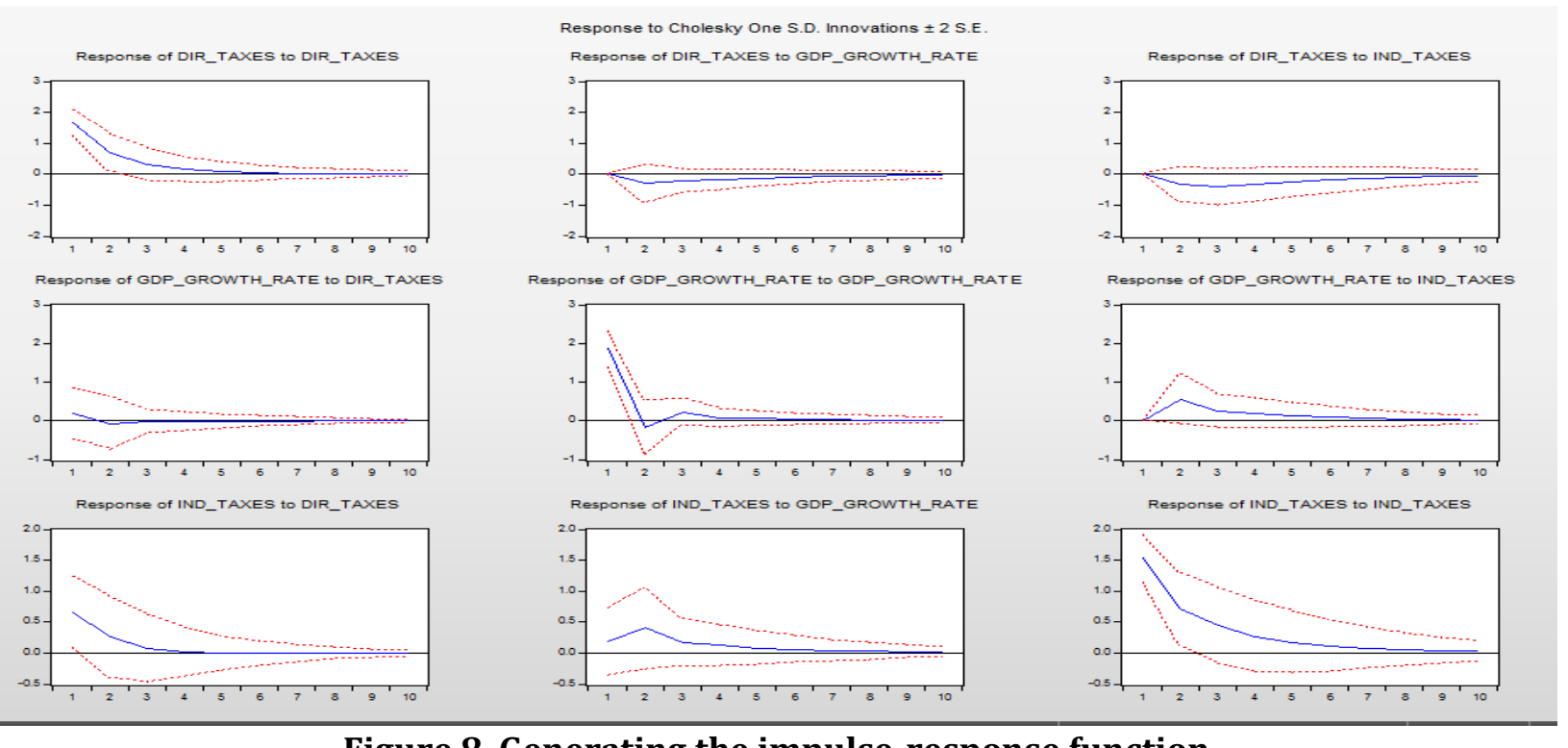

Figure 8. Generating the impulse-response function

Source: Author's own research.

The response of gdp_growth_rate to dir_taxes indicated that a positive change in the level of direct taxes would have a negative impact on the gdp_growth_rate starting with the first quarter of forecasting time period. The impact would tend to increase and to reflect a positive correlation on the gdp_growth_rate from the second quarter period, then maintaining a steady level over a long run term. It was revealed that as soon as a positive shock occurs within the structure of the direct taxes, it would have a negative impact on the economic growth for a short-term and then would maintain a constant positive level over a medium or long-term.

The response of gdp_growth_rate to ind_taxes indicated a positive impact on the gdp_growth_rate variable from the first quarter of forecasting time period. This significant impact would maintain until the $6^{\text {th }}$ quarter and then maintaining a steady positive longterm impact over the future time period. Thus, it was revealed that a positive change in the value of indirect taxes have a significant positive impact while direct taxes have a less significant impact on economic growth in Romania over some future term periods.

\section{Conclusion}

This paper presented an empirical model using an econometric Vector Autoregressive model to analyze the impact of the change in the value of direct taxes and indirect taxes on economic growth by using statistical time series data related to Romania over the period of 2009 ( $2^{\text {nd }}$ quarter) -2017 ( $2^{\text {nd }}$ quarter). As revealed by using the impulse response function, there is a less significant impact of changing the value of direct taxes on economic growth. On the other hand, indirect taxes will positively influence economic growth in the Romanian economy even from the first quarter of estimation of any positive change in the structure of indirect taxes. Although the endogenous variables presented in the VAR model are relevant to explain the analyzed econometric model, the changes in direct and indirect taxes should not be regarded as the only factors that may affect economic growth due to the 
fact that the macroeconomic variable of economic growth could be influenced by many other decisive factors. However, the fiscal policy implemented by the state remains a strong pillar in the increase of public financial resources, in the possibility of subsequent sustaining of public expenditures alongside with the probability of revealing a sustainable economic growth and maintaining an economic consolidation and stabilization for the state.

\section{References}

Arnold, J. et al. (2011). Tax policy for Economic recovery and growth. Economic Journal, Royal Economic Society, vol. 121(550), F59-F80, February.

Arnold, J. (2008). Do Tax Structures Affect Aggregate. Economic Growth?: Empirical Evidence from a Panel of OECD Countries, OECD Economics Department Working Papers, No. 643, OECD Publishing, Paris.

Brașoveanu, L.0., \& Brașoveanu, I., (2008). The Correlation between fiscal policy and economic growth, Theoretical and Applied Economics, Asociatia Generala a Economistilor din Romania - AGER, 7(524), 19-26, July.

Brooks, C. (2014). Introductory Econometrics for Finance ( $3^{\text {rd }}$ ed.), Cambridge : Cambridge University Press.

Desislava, S. (2017). Tax structure and economic growth: Evidence from the European Union. Contaduría y Administración, 62(3), 1041-1057.

European Center Bank (2017). Euro area fiscal stance, Occasional paper series, no. 182, Brussels, January.

European Commission (2017a). Government finance statistics - Summary tables data 1995-2016, No. 2/2017, Brussels: The EU Commission.

European Commission (2017b). European Economic Forecast Spring 2017, Romania - Growth momentum maintained amid fiscal deterioration, Brussels: The EU Commission.

European Commission (2017c). Assesment of the 2017 Programme for Romania, Brussels: The EU Commission.

European Commission (2016). Taxation Trends in the European Union, Brussels: The EU Commission.

European Commission (2013). European system of accounts - ESA 2010, p. 428, Brussels: The EU Commission.

European Commission (2011). Tax reforms in EU member states: Tax policy challenges for economic growth and fiscal sustainability, European Economy Series 5/2011, Brussels: The EU Commission.

European Commission (2006). Macroeconomic effects of a shift from direct to indirect Taxation: A simulation for 15 EU Member States, OECD Working Party, No. 2 Tax policy Analysis and Tax Statistics, Paris, November.

Eurostat database (2017). Data Explorer retrieved on http://ec.europa.eu/eurostat. Gujarati, D. (2004). Basic Econometrics (4th ed.), New York: The McGrow Hill Companies, Kamps, C., Cimadomo, J., Hauptmeier, S., Leiner-Killinger, N. (2017). Reflections on the Euro Area Fiscal Stance, 52(3), 125-131.

Mura, P. (2015). Tax composition and economic growth. A panel-model approach for 
Eastern Europe, Annals of the „Constantin Brâncuși” University of Târgu-Jiu, Economy Serie, 2(1), 89-101.

Mutașcu, M.I. \& Dănulețiu, D.C. (2011). Taxes and economic growth in Romania.

A VAR Approach, Annales Universitatis Apulensis : Series Oeconomica, 13(1), 94.

Romer, D. (2012). Advanced Macroeconomics (4th ed.), New York: McGrow Hill Companies.

PICBE | 127

Stailova, D., \& Patonov, N. (2012). An empirical evidence for the impact of taxation on economy growth in the European Union, Tourism and Management Studies, $3,1030-1039$.

Szarowska, I. (2011). Changes in taxation and their impact on economic growth in the European Union, Munich Personal RePEc Archive Paper No. 32354, July retrieved on https://mpra.ub.uni-muenchen.de/32354/.

Szarowska, I. (2013). Effects of taxation by economic functions on economic growth in the European Union. Proceedings of the 6th International Scientific Conference: Finance and the performance of Firms in Science, Education and Practice No. WOS:000329435800063, 746-758 retrieved on https://mpra.ub.unimuenchen.de/59781/. 